\title{
Marketing communication analysis of benetton PR campaigns
}

\author{
Cynthia Bianka INCZE \\ The Bucharest University of Economic Studies, Bucharest, Romania \\ incze_cynthia@yahoo.com
}

Alexandra POCOVNICU

The Bucharest University of Economic Studies, Bucharest, Romania

alexandra.pocovnicu@gmail.com

Simona VASILACHE

The Bucharest University of Economic Studies, Bucharest, Romania

simona.vasilache@gmail.com

Nora-Labiba AL ZAIN

The Bucharest University of Economic Studies, Bucharest, Romania

alzain.nora@gmail.com

\begin{abstract}
In today's economies the role of marketing cannot be underestimated, just the sole amount of media communications is astonishing not taking in consideration the different marketing and PR strategies involved. The most well-known tools include advertising, public relations, sales promotions, direct marketing and personal selling. There is an increasing number of advertisements that reach our attention by the presence of vulgarity, nudity or moral offenses. The aim of the article is to extensively review the literature of shock advertising namely shockvertising and to pinpoint its evolution in case of Benetton fashion brand. Shockvertising focuses on the idea of selling products through evoking terrifying and repulsive emotions. This type of advertising is used to sensitize people to religion, racism, war, poverty and other taboo topics. The descriptive method is used in order to describe such complex phenomena. The research is conducted in the form of a retrospective qualitative case study focusing on the historical events that are connected to the communications at Benetton. Through the following research a better understanding of shockvertising and its dynamics is reached and emotional reactions of a range of individuals is presented. In addition, the question of ethical considerations and the shock advertising effectiveness is analyzed.
\end{abstract}

Keywords: shockvertising, marketing, PR, Benetton, ethics, media.

\section{Introduction}

Advertisements were always blamed for manipulation and for creation of false needs focusing on increasing consumerism and less focus on social problems (Haug, 1989, Kellner, 1990).

In the nineties some companies started to outstand from the crowd by producing advertisements with strong social and political messages, thus developing the today wellknown shock advertisement. The main pioneers of shockvertising includes Benetton, Diesel and the Body Shop.

Opinions on shocking ads are highly divergent. Some people approve schockvertising due to its eye opening effect and the highlighting of the real social issues globally, while others believe that shockvertising relies heavily on emotional manipulation and companies gain using social issues commercialization in their own favor. 
In this article the importance of public relations, the phenomenon of shokvertising and its ethical issues are presented through a case study of the Benetton Company.

\section{Literature review}

In 1987, the UK Institute for Public Relations formulated a PR definition that is still relevant today as: "Public Relations is the planned and sustained effort to establish and maintain goodwill and understanding between an organization and its publics." The definition has gradually extended to "Public Relations is the discipline concerned with the reputation of organizations (or products, services or individuals) with the aim of earning understanding and support."

The best regarded companies build their reputations by developing practices that integrate economic and social considerations into their competitive strategies. They do not only do things right, but they do the right things. They are supposed to act in ways which reflect their core values that consider the joint welfare of all stakeholders (Fombrun, 1996).

Public relations can accomplish a number of important objectives, it can foster prestige and reputation, attract and keep good employees, promote favorable community relations and can have a key role in fostering goodwill and relational capital among customers, employees, suppliers, distributors and government (Jobber \& Fahy 2009, p.232). Relational capital can be built by expressing a company's culture, values and best practices by communicating with stakeholders (Gulati et al., 2002).

Public relations constitute a management function which helps establish and maintain mutual lines of communication, understanding, acceptance and co-operation between an organization and its publics. Although PR and advertising go hand in hand, their goals and overall effect are completely different. While advertising is exclusively concerned with the promotion of products or services and its main goal is to encourage the consumer to purchase, PR is specialized in communication with the public. PR often helps increase the sales of a company but it is mainly focused on creating positive publicity regarding an organization, as well as maintaining the positive image created.

Shockvertising composed of the words shock and advertising is a term referring to the use of provocative, controversial, disturbing or explicit content in order to attract the consumer's attention in the clutter of competition. Advertisers hope to sell their products by horrifying, terrifying, offensive, repulsive, taboo and emotion-provoking images, and evoking feelings among consumers. This type of advertising is used to sensitize people to religion, racism, war, poverty and other taboo topics.

According to Dahl and Manchanda (2003, cited in Halvadia et al.), shockvertising offends by using norm violation, such as law or customs disobedience, going against social or moral code or things that outrage the moral senses, like profanity, vulgarity, indecent sexual references, disgusting images or gratuitous violence.

The success of a shocking campaign depends on the context, product and the message of the campaign desired to get across. Companies using shockvertising get more media coverage, because of the shock value. Although the risk is high that the amount of shock and disgust is high enough to make people look away and could develop a negative image, companies that engage in shockvertising voluntarily are usually aware of the feelings they will evoke and the controversy they will give birth to. Shockvertising can 
severely impact the relational capital (the approach to communicate and get closer to stakeholders) and goodwill of the company.

When it comes to shock advertising, ethical issues are of central importance, especially when most advertisers deliberately choose to shock the audience. In order to use shock value, they break taboos and violate societal and personal norms. Other than that, taste and decency are of particular interest when it comes to ethical considerations (Pickton et al., 2005).

There are several arguments supporting the use of shock advertising, mainly due to the immediate and long lasting effect on the audience, having a rapid effect and naturally attracting attention. Results of interviews after exposure to different kind of advertisements show that shocking content significantly increases attention, benefits memory and positively influences behavior (Dahl et al., 2003, as cited in Halvadia et al., p.34).

According to Kotler (2005, p. 771), controversial advertising campaigns are a way of breaking through the clutter and create brands but on the other hand, controversial campaigns risk negative association with their brands can lead to discouraging consumers to engage in any relationship with the advert issuer.

"In a connected world," according to Seidman, "...companies also have character, and their character-how they do what they do, how they keep promises, how they make decisions, how things really happen inside, how they connect and collaborate, how they engender trust, how they relate to their customers, to the environment and to the communities in which they operate-is now their fate." (Van Riel et al., 2007)

Although academic practitioners' literature provided effectiveness of this communication strategy, both in terms of generating attention but also in terms of influencing attitudes and behavior of the recipients, it remains a question of whether this type of communication strategy would be equally effective in different cultures.

\section{Methodology}

The goal of the study is to provide a full understanding from multiple points of view of the communication between Benetton Group and the publics. Some of the questions that are addressed are why did Benetton choose to communicate with their publics the way it did, how their communications strategy changed over time, how did the publics respond to such communications and how did the relationship between Benetton and the customers changed and why.

The research method used is qualitative case study, as it is a descriptive method providing the means of understanding such complex phenomena. The study is not exclusively used on qualitative data, but it also included reviewing quantitative data, especially regarding the repercussions of the campaigns. It is the method which provides a multifaceted understanding of the phenomena and focuses on questions "Why" and "How" (Baxter et al., 2008, p.544). Also, it is a retrospective case study, as opposed to a prospective case study, focusing on the historical events that are connected to the communications at Benetton.

Secondary sources of information sources were used in the present study. Numerous journal articles and reviews were consulted. Tertiary sources such as dictionaries, encyclopedias or handbooks were also used, for gaining a general overview of the subject. 
The research is not exhaustive, thus further analysis can be performed in the form of qualitative research by analyzing other companies embracing shockvertising such as Diesel or the Body Shop. Also, through quantitative analysis the financial implications such as advertising costs and revenue growth though a time frame can be compared.

\section{The analysis of Benetton campaigns}

Benetton has historically pushed boundaries using imagery and narratives colliding with taboos and unpopular issues. The company strives to promote itself as a socially responsible business and is well known for unusual advertising themes and techniques, frequently using shock value for addressing controversial social and political issues such as racism, AIDS awareness, child labor, and pollution, genocides in Africa, Gulf War casualties, or homosexuality. Although they were appreciated by the strong statements thought as methods of raising awareness of sensitive issues, they are also seen as offensive by viewers in various cultures.

It is said that only brands of strong stature can use their power of influence to bridge the gap between accruing financial success and communicating a sincere message (Thomas, 2012).

Right from the beginning, in the 80s, Benetton chose the path of unconventional communication strategy. As the company's documents reveal, "Benetton believes that it is important for companies to take a stance in the real world instead of using their advertising budget to perpetuate the myth that they can make consumers happy through the mere purchase of their product."

Luciano Benetton's made a statement that "communication should never be commissioned from outside the company, but conceived from within its heart", while the photographer and creative director of Benetton Group, Olivier Toscani stated that he believes "just advertising a product is a waste of communication."

\section{The evolution of sustainable marketing communications at Benetton The 1980 s campaigns}

In 1984 Benetton expanded its advertising outside Italy and France with a campaign titled "All the Colors of the World." This campaign led way to the name "United Colors of Benetton". The ad featured teenagers of various ethnicities, wearing the company's clothing, laughing and generally sending the message of happiness and harmony in unity.

Although it presented an ideal, the company's management figured the advertising strategy is naïve and not inciting enough in the light of the social realities, the world being caught up in famine, war, violence and employing in nationalism and racism, and their market research which indicated that its target customers, 18-34 year old women, are more aware and socially active than any generation before them, and "are concerned by what a company stands for as they are about the price/value relationship of that company's product" provided more room for even stronger social messages (Giroux, 1994).

Advertisement costs were lowered at one third in comparison to the cost of their competitors. The merchandise completely disappeared from the ads and Toscani adopted the "United Colors of Benetton" as a recurring trademark of the company's ideology. The company's ads featured symbolic photographs such as a white and a black hand cuffed 
together, a black woman breast-feeding a white baby, or an African-American child taking a nap on a pile of white teddy bears.

\section{The 1980s campaigns}

In 1991 Toscani started using an eighty million dollar global ad budget to continue publishing controversial photographs in magazines and on billboards. The photographs created an unseen provocative effect as they were related to controversial realities such as AIDS crisis, political violence, war or environmental disaster. Other photos showed closeups of different parts of the human body such as pubis, arms, stomach, tattooed with "HIV Positive". These appeared on print media and billboards, having no written text except for the green and white Benetton logo.

The advertisement of a black stallion mounting a white mare was banned from all sites by two of the biggest outdoor board contractors in Europe. French group Avenir and British contractor Mills \& Allen have turned down the ad on moral grounds.Also, an ad with a picture of a nun and a priest kissing on the lips angered the Roman Catholic Church and was promptly banned by the Italian Advertising Authority. On the other hand, the advertisement won the Eurobest Award, being appreciated in England.

Another advertisement, featuring three children coming from different ethnic groups, sticking their tongues out was withdrawn from display in Arab countries, as it was considered pornographic to display an internal organ.

None of the campaigns from 1984 through 1991 caused more controversy than the 1992 campaign, which used photographs of actual historic moments, taken by prominent independent photojournalists (Boches, 2011). The photographs have no written message beside the green and white Benetton logo.

Family - an advertisement showing David Kirby, a 32 years old AIDS victim, surrounded by his grieving family on the deathbed, was also highly controversial and gave birth to immediate reactions. The advert was deemed not to be highlighting the reality of AIDS, but an attempt to gain brand recognition and arouse sympathy at the expense of a man dieing of AIDS. It was felt that Benetton should not gain brand recognition or make profit from raising such issues. The company's profits have risen twenty-four percent to 132 million dollars that year (Giroux, 1994).

The UK ASA described the ad as being "a despicable exploitation of a tragic situation." Also, the editor of the UK version of ELLE, who ran a two-page statement instead of the ad, decision that reportedly cost the magazine nearly 150,000 dollars in lost ad revenue commented for The Guardian (1992) that the ad is insulting for a fashion store and stepped out of the bounds.

The other Benetton advertisements included a large crowd of black refugees in a container of garbage, a bombed car in flames; duck covered in oil from a spill, very young children making bricks etc.

Benetton explains in a statement appearing in their FW 1992 advertising campaign:

"...we at Benetton believe our strategy for communication to be more effective for the company and more useful to society than would be yet another series of ads showing pretty girls wearing pretty clothes." 
But the shockvertising card has not entirely satisfied its commercial needs, as franchise holders in Germany and France have gone to courts, complaining the ads has sent sales into freefall. Also, in Italy, the "Heart-to-heart (to heart)" ad showing three hearts labeled white, black and yellow was blamed for reinforcing fears over organ transplants and even prompted the UK's self-regulatory Advertising Standards Authority to issue an Ad Alert, urging magazines and newspapers to contact it for advice before accepting the ad, depending on the publication's target audience.

\section{The “UNHATE” campaign}

The UNHATE campaign was launched in November 2011 and the idea behind the campaign was "contrasting the culture of hatred and promoting closeness between peoples, faiths, cultures, and the peaceful understanding of each other's motivations" used computeraltered photographs of world leaders, often seen as adversaries, kissing one another on the lips. Some of the people in the lip-lock campaign are Barack Obama and Chinese leader Hu Jintao, Palestinian President Mahmoud Abbas and Israeli Prime Minister Benjamin Netanyahu.

The campaign was supported by other forms of advertisement, such as film, guerilla actions worldwide showcasing the digitals where a Kiss Wall is created, people being invited to share their own lip-lock pictures and opinions, a Twitter-based list promoting what and who people do not hate. It is in a way encompassing an entire Unhate ecosystem (Anand, 2011).

The ad that generated the most reactions involved Pope Benedict XVI and a prominent Islamic cleric, Sheikh Ahmed Mohamed el-Tayeb, Imam of the Al-Azhar institute in Cairo, Egypt. After legal threats by the Vatican, Benetton made the decision to pull the ad (Murray, 2011).

"This shows a grave lack of respect for the pope, an offence to the feelings of believers" said Vatican spokesman, Federico Lombardi. In an official statement Benetton apologized for the use of the image of the Pope and the Imam.

Another reaction came from the Retail Prophet President, Doug Stephens, who commented: "As a consumer I'd be more interested in knowing what Benetton is doing as a company to make the world a better place or how my aligning with their brand values makes me a better person. I don't get any of that from this campaign."

However, the campaign had a significant impact on the international community reaching a total of 500 million users worldwide, more than 3000 articles and 600 TV reports in 60 nations as traditional media reactions. In the online environment the campaign became in only a few weeks one of the top five Google and Twitter topic trends and generated an increase of $60 \%$ in the number of fans on the brand's Facebook page.

The UNHATE campaign received the Press Grand Prix at the Cannes Lions International Festival of Creativity in June 2012. Although the ads won the best international print campaign, the amount of controversy shows that the audience carries mixed feelings about them (Ganesan, 2002).

Although it can be pleated that the company's products were qualitative and popular, it is interesting to see that the Benetton group's sales only risen 2 percent in the past 10 years. In the United States alone, sales dropped from 12\% in 2000 to $4 \%$ at the end 
of 2010 (Rodriguez, 2011). Just before the campaign was launched, Benetton encountered net income fall of $33 \%$ to 42.3 million dollars.

Most critics feel that Benetton "missed the boat" with the UNHATE campaign, going purely for shock value and losing all sight of their main goal. Although Benetton's intention was to promote unity and fight hate and discrimination, such a campaign was sure to stir up the latter. (Del Rosario, 2013, p.1)

PICBE $\mid 463$

Both legal and moral issues were raised. The legality of the campaign was questioned first of all since it uses individuals who have not given their permission to appear in the campaign, which appear doing something they most definitely did not do, in computer altered pictures. The ads have been criticized for being altered in a material way without any written warning, violating the principle of truth in advertising.

Also, the morality behind the campaign was questioned. Portraying two men sharing a "fake" intimate kiss is still not seen as a norm, and in the case of the religious leaders, they are portrayed as doing something contrary to what their religions teach.

\section{Conclusion}

It is a common place for organizations to use social causes in their attempt of generating good will. There are headlines showing companies sponsoring marathons, nonprofit events and humanitarian causes, but are these only a ploy to gain brand attention and press coverage, or there is a higher purpose?

No brand is able to carry ideas across cultures than Benetton does, demonstrating the ability of opening pertinent debates, raise attention to obvious issues, often unpopular in the public eye, in a fusion of social-issues advocacy and sales promotion, wrapped in a package that incites public controversy.

When going international, companies face new communication and ethical challenges due to cultural relativism. An important ethical issue is related to the cultural context in which advertisements based on shock value are released. While a provocative advertisement may be seen as normal in one culture, it may be seen as extremely offensive in another, more sensitive culture. Different countries within the company's target market have different levels of acceptance, and the world is not such a "united" place as their utopist first campaigns (Bogerson et al., 2009).

The effect of the 1990s campaigns was immediate - the customers felt that they were "purchasing a philosophy", they felt satisfied for purchasing products from a brand that has put social problems above brand promotion, the company's net sales sky-rocketed at first (Tinic et al., 1997, p.21.). On the other hand, as much as they rose, they crashed down during the course of the controversial campaigns. Although Benetton was sued by many retail outlets, which figured the advertisements drive away customers instead of attracting them, the more the campaigns were banned, the more publicity Benetton managed to get.

Today Benetton seems wiser, a wiser and more equilibrated company that does not feel the need to shock the audience to force it into social justice discussions. The shock advertising employed at Benetton does not follow the conventional path of using either focusing on a product or a desired behavior, but it employed an approach based on shared values and perceptions of an organization with the market segment addresses to. It introduced a series of programs it hopes will eventually contribute to a culture of tolerance, 
including educational programs and support for NGOs promoting tolerance, efforts to promote human rights, women empowerment and support for art programs.

Benetton also understood that relational capital is beyond reputation. Reputation in itself represent just an image, however relational capital is about the dynamics. For a sustainable future it is important to become deeply connected and aim beyond tactical, transactional or limited relationships. Benetton through it's controversy advertising and campaigns managed to start meaningful discussions and deepen the relationship with its stakeholders.

We would have expected a "Benetton Foundation for Bosnian Victims' Families", or an AIDS Victims Charity Fund, but the harsh truth is that in the 80s and 90s Benetton campaigns, it was only bright colored jumpers behind the whole buzz, without charitable actions being promoted in any way. Not one of the advertisements had text such as "For every sweater bought, 1 dollar goes to AIDS fund or pollution fund". The campaigns eventually began to cause a high level of dissatisfaction among customers, retailers, nonprofit organizations and government bodies.

The communications strategy at Benetton targets issues than clothes, with a small portion of the advertising budget being devoted to communicating social issues. Benetton has developed advertising campaigns that are international, characterized by universal themes. Through its universal impact, the company managed to attract the public's attention and has succeeded in standing out among the clutter of images, proving the sustainability of its advertising concept.

\section{References}

Baxter, P., \& Jack, S. (2008) Qualitative case study methodology: Study design and implementation for novice researchers. The qualitative report, 13(4), 544-559.

Boches, E. (2011) Three ways to look at Benetton: the cause, the creative, the controversy, Creativity Unbound. Retrieved from http://edwardboches.com/three-ways-to-lookat-benetton-the-cause-the-creative-the-controversy.

Bogerson, J.L., Schroeder, J.E., Magnusson M.E., Magnusson F. (2009) Corporate communication, ethics, and operational identity: a case study of Benetton, Journal of Business Ethics 183(3), 209-223.

Del Rosario, R.J. Ethics of Advertising- Unhate: Is it Possible?, Retrieved in January (2016) from: http://www.scribd.com/doc/170706721/Ethics-of-Advertising.

Fombrun, C.J. (1996) Reputation: Realizing Value from the Corporate Image, Harvard Business School Press, Boston.

Ganesan, S. (2002) Benetton Group: Unconventional Advertising. Global CEO. Retrieved in June 2016 from: http://teach.beaverton.k12.or.us/ emily_ramberg/FOV10006F6A0/FOV1-0008BE28/Benetton\%20Article.PDF.

Giroux, H.A. (1994) Benetton's "World without Borders": Buying Social Change, New York: Routledge.

Halvadia, N. Patel, V. \& Patel, S. (2011) Shock advertising and its impact, International Journal of Sales and Marketing Management, 1(1), 30-36.

Haug, W. (1986) Critique of commodity aesthetics: appearance, sexuality and advertising in capitalist society, Minneapolis University of Minnesota Press. 
Gulati, R., Huffman, S., Neilson, G. (2002) The Barista Principle - Starbucks and the Rise of Relational Capital, Strategy and Leadership, Retrieved in January 2018 from: https://www.strategy-business.com/article/20534?gko=582b3.

Jobber, D., Fahy, J. (2009) Foundations of Marketing, Third Edition, MCGraw-Hill.

Kellner, D. (1989) Critical theory, Marxism and modernity, Baltimore, John Hopkins University Press.

PICBE | 465

Kotler, Ph. (2005) Principles of Marketing, Financial Times Prentice Hall

Murray, R. (2011) "Benetton yanks smooching Pope ad from Unhate campaign after Vatican threatened legal action." New York Daily News. Retrieved in January 2018:

http://www.nydailynews.com/life-style/fashion/benetton-yanks-smooching-popead-unhate-campaign-vatican-threatened-legal-action-article-1.979430.

Pickton, D., Broderick, A. (2005) Integrated Marketing Communications, Second Edition, Prentice Hall.

Van Riel, Cees B.M., Fombrun, Charles J. (2007) Essentials Of Corporate Communication,Abingdon \& New York: Routledge.

Rodriguez, M. (2011) Benetton's unhate campaign misses its mark. Retrieved in June 2017 from: http://lorriewalkerpr.com/2011/12/benettons-unhate-campaign-misses-itsmark/.

Thomas, C. (2012) Tag Archives: United Colors of Benetton. Retrieved in June 2017 from: http://contingentoncool.wordpress.com/tag/united-colors-of-benetton/.

Tinic, Serra A. (1997) United Colors and United Meanings: Benetton and the Commodification of Social Issues, Journal of Communication 47(3), 3-25.

Anand, T. (2011) Benetton's shock treatment works, say creatives. Retrieved in January 2018 from: http://www.mxmindia.com/2011/11/benetton-\%E2\%80\%93-the-kissthat-didn\%E2\%80\%99t-work/. 